\title{
Improving Community Knowledge and Attitude towards PulmonaryTuberculosis in Zagazig District- Sharkia Governorate through Application of Interventional Health Education Program
}

\author{
Sohair A Hagag , Mona M Abosrea and Shereen Eassa \\ Community, Environmental and Occupational Medicine Department, Faculty of Medicine, \\ Zagazig University, Egypt
}

Corresponding Author

Sohair A Hagag

E mail:

dr.sohierhagag@yaho o.com

Received :27/4/2012 Accepted after revision: $18 / 5 / 2012$

Key words: improving, pulmonary tuberculosis knowledge, attitude, health education.
Background and study aim: Egypt has achieved treatment success rates higher than the WHO-recommended target of 85 percent. However the case detection rate of about 50 percent remains below the 70 percent target. This is due to low awareness of population about tuberculosis, delay of patients medical advice about chest symptoms, and lack of coordination between different health sectors. The aim of this study is to clarify knowledge and attitudes regarding pulmonary TB among population of Zagazig district in Sharkia governorate, and to assess the effect of a community intervention health education in improving their knowledge and attitudes about pulmonary TB.

Patients and methods: Survey was conducted on 254 individuals from both sexes $\geq 18$ years old in Zagazig district, Sharkia governorate. A questionnaire for Knowledge and attitude about pulmonary tuberculosis was adapted from ( Advocacy, Communication and Social Mobilization for TB control /A guide to developing knowledge, attitude and practice surveys). Then an intervention health education program was implemented and evaluated after three months.

Results: The study revealed that $61.4 \%$ of adults of both sexes had unsatisfactory knowledge about tuberculosis. Only

\section{INTRODUCTION}

Tuberculosis is re-emerging global health problem in need to have better understanding by communities. Africa currently carries a huge burden of tuberculosis (TB) which estimated at $30 \%$ of the total global number of TB cases and coming second after Asia $(50 \%)$, where approximately $41 \%$ of the highest burdened countries with TB worldwide were found in Africa [1]. Other compounding factors, apart
(16.5\%) were aware that diagnosis and treatment of tuberculosis were free of charge. The correct duration of standard treatment was reported by $(21.7 \%)$ of studied group. Only 54.3\% of study group seeking treatment at a health facility, when feel symptom. About $62.3 \%$ were more likely to feel fear and embarrassed if being a TB patient. However, about $60.2 \%$ of study population seem to be supportive to tuberculosis patients. The main source of acquired information about tuberculosis were television $(54.7 \%)$. Regarding the effect of the health education intervention on knowledge of the studied group; there were statistical significant improvement in knowing the mode of transmission of pulmonary TB, place of treatment, and its duration after health education program $(p<0.05)$. The studied group who had satisfactory knowledge about pulmonary tuberculosis was doubled after health education program.

Conclusion: The survey results showed that the overall knowledge regarding TB was unsatisfactory in the studied population. After health education program there is improvement of knowledge regarding TB among studied group.

from HIV, that have resulted in the increasing trend of TB in Africa are poverty, which is closely related to malnutrition, crowded living conditions, lack of access to free or affordable healthcare services, and dependence on traditional healers that can facilitate the transmission of tuberculosis [2]. WHO is working to reduce the burden of $\mathrm{TB}$, and halve TB deaths and prevalence by 2015 . 
Through its stop TB strategy and supporting the global plan to Stop TB. Despite the qualityassured $\mathrm{TB}$ services in line with the stop TB strategy [3]. TB case detection is incomplete, the global TB burden remains high and TB incidence is declining slowly worldwide [4]

Egypt is considered one of the high-burden countries in eastern mediterranean region[5]. In the past the Egyptian government organized TB control through its network of chest care facilities. Then government established the National TB Program (NTP) in an attempt to provide more efficient and effective TB control services. Through primary health care units, health insurance organizations, university hospitals, and prison facilities have been involved in the effort to expand awareness, which now reaches 100 percent of the population. The NTP has become a model of TB control for middle income countries in the region and now provides training courses targeted to international audiences. While Egypt has achieved treatment success rates higher than the WHO-recommended target of 85 percent. But the case detection rate about 50 percent which remains below the 70 percent target. This due to low awareness of population about tuberculosis, delay of patients medical advice about chest symptoms, lack of coordination within different health sectors[6].

In Egypt the principal risk factors for treatment failure of pulmonary tuberculosis were noncompliance to treatment, due to deficient health education and poor knowledge about the pulmonary TB disease [7].

Ensuring high awareness in communities about health in general and pulmonary $\mathrm{TB}$ and $\mathrm{TB}$ services in particular is the cornerstone in proper management of tuberculosis patients. People must be aware about TB symptoms and take appropriate action early, by seeking care from the available health facilities. More importantly, people need to know that, the available health services offer something valuable at an affordable cost [8]

\section{Aim of the Study}

To improve awareness of population about TB and consequently helping in early case detection and improving their compliance to treatment.

Objectives: To clarify knowledge and attitudes regarding pulmonary $\mathrm{TB}$ in population of Zagazig district in Sharkia governorate, and to assess the effect of a community health education program intervention in improving knowledge and attitudes about pulmonary TB.

\section{PATIENTS AND METHODS}

Study design: It was carried out in two phases

Phase one: survey part

Phase two: intervention part

Setting: it was carried out at Zagazig district, Sharkyia Governorate- Egypt .

Sampling technique: A multistage systematic random sampling design was adopted for the current study. Zagazig district was divided into rural and urban regions; El Zohor region was chosen randomly (urban part). Two villages were chosen as rural part; (Tahlet Bordin, and Tarout) (1st sampling stage). Then each selected place was divided by main landmarks into four geographical sectors, then one sector was selected randomly from each place (second sampling stage). Each sector was divided into main streets, three streets were chosen randomly (third sampling stage). Each house in the selected streets was given a code and recorded in a prescribed forms for the study to facilitate the follow up assessment of the sample. Then every third house was taken randomly after selecting the 1st one randomly from the 1st three houses .

Sample size was calculated by using Epi-info version (6.04);

- At the 1st stage (survey part):

Population at Zagazig district at or above the age of 18 years were 848000 . Urban to rural population ratio=1:4. Percent of satisfactory knowledge about $\mathrm{TB}=42.6 \%$ [9], at test power $=80$ and $95 \%$ CI. Accordingly, the estimated sample size $=254$ persons .

The target population: adults aged $\geq 18$ years, both sexes and permanently residing in the selected places.

Data collection tools: structured questionnaire was used which included; Socio-demographic data such as age, gender, education, occupation, income.

Questions for knowledge and attitude about pulmonary tuberculosis which were adapted from. Advocacy, Communication and Social Mobilization for TB control /A guide to developing knowledge, attitude and practice 
surveys[10]. It was translated into Arabic language.

Knowledge about pulmonary tuberculosis: This part included questions about TB symptoms, mode of transmission, and duration and cost of treatment, seriousness of $\mathrm{TB}$ and methods of prevention. The sources of information about TB. knowledge score for each question ranges from 0 for incorrect knowledge to 1 for correct one. Total minimum score $=0$ and total maximum knowledge score $=10$. The median knowledge score for the study population was calculated. The participants who were knowledge score above the median were classified as having satisfactory knowledge about pulmonary tuberculosis. However those who had knowledge score equal or below median were classified as having unsatisfactory knowledge about pulmonary tuberculosis .

Attitude towards pulmonary tuberculosis: This part included four questions about attitude of studied subjects if they assume themselves to have pulmonary tuberculosis. The questions included; What they would do if they thought they had TB symptoms? When participants go to health services? How TB patients are regarded in their community? And what would their reaction be if they found out that they have TB?.

\section{Fieldwork}

After obtaining official permissions to undertake the study. The pilot- study was done to test the feasibility of questionnaire and time needed to answer it .

Phase one: The researchers started the survey : met the selected subjects, explained to them the purpose of the study, and solicited their participation after obtaining their oral consent. Then interview was done using the prepared questionnaire as a pre-test. Each pretest interview took about 15 minutes to fill the questionnaire. An appointment was scheduled for each subject to meet at the related primary health care unit for implementing health education program.

Phase two: an intervention health education community based program, with pre and post assessment.

- Intervention part of the study (2nd stage) included the following:

the sample size: was calculated to detect an improvement in subjects knowledge and attitude related to pulmonary tuberculosis from a preintervention level of $38 \%$ to an expected postintervention level of $65 \%$, with a $95 \%$ level of confidence, and power of test $80 \%$. Accordingly, the estimated sample size was 60 subjects .

Analysis of the obtained pre-test data was done. Then, the researchers designed the health educational intervention program, which was adopted from the National tuberculosis program [6]. It included clear message, with simple brochures, power point presentation and posters to explain all the items of knowledge and attitude regarding Pulmonary TB. It was delivered to the individuals through face-to-face method as lectures in the related primary health care unit. Brochures were distributed to remind the recipients of the health messages about pulmonary tuberculosis. Then, a posttest was done after 3 months on the same individuals using the same pre-test interview form in order to assess the changes of their, knowledge and attitude after the intervention.

Statistical analysis: Data entry and analysis were done by using Epi-Info 6.04 and SPSS version 19 computer software packages. Data were presented using descriptive statistics in the form of frequencies and percentages for qualitative variables, and means and standard deviations for quantitative variables. Categorical variables were compared using Mc Nemar chisquare test (paired qualitative data). Statistical significance was considered at $\mathrm{p}$-value $<0.05$.

\section{RESULTS}

As regards to socio-demographic characteristics of the 254 individuals, $50.4 \%$ were males and $49.6 \%$ were females. More than three quarters were married. The majority of the studied subjects were residing in rural areas $(78.7 \%)$. About three quarters of the studied group were $\leq$ 40 years old. The majority of studied group were from high social class (48.8\%) followed by middle social class (31.5\%). About $14 \%$ of studied group were smokers.

The mean knowledge score about pulmonary tuberculosis among the studied population was $5.8 \pm 1.65$, (median (6) , range (1-9). Only $38.6 \%$ of participants had Satisfactory knowledge. It was found that males had higher and statistically significant satisfactory Knowledge about pulmonary TB compared to females $(44.5 \%$ and $32.5 \%$ respectively) as demonstrated in table (1). 
Symptoms, transmission and prevention of pulmonary tuberculosis: the Interviewed subjects identified that; cough $>3$ weeks as the presenting complaint for pulmonary TB $(41.7 \%)$, air borne the main mode of transmission of pulmonary TB $(73.2 \%)$, in addition to $31.1 \%$ of them reported that covering mouth and nose during coughing or sneezing as the main preventive measure, as shown in figure (1).

Regarding pulmonary tuberculosis treatment: the majority of interviewees $(79.1 \%)$ mentioned that treatment of tuberculosis by specific drugs were provided by health centers. Only $21.7 \%$ of the interviewed persons mentioned that treatment duration of pulmonary TB was 6-9 months. About $70 \%$ of the studied individuals knew that tuberculosis was treated at government hospitals. Whereas $16.5 \%$ of them described that diagnosis and treatment of tuberculosis were free of charge as in figure (1).

Seriousness of pulmonary TB: $37 \%$ of the studied subjects reported that pulmonary TB is a dangerous disease and about $67 \%$ considered pulmonary $\mathrm{TB}$ as a moderate prevalent health problem in Egypt as in figure (1).

The main information sources about pulmonary tuberculosis were television (54.7\%), health care providers $(17.7 \%)$, then newspapers and posters (15\%) figure (2).

As regards to attitudes and intended healthseeking behavior; The majority of the studied group (81.5\%) answered that they would go to a health facility if they thought that they had TB as in table (2). Early seeking behavior when they feel symptoms of pulmonary TB among 54.3\% of the studied group.

In the current study, $60.2 \%$ of the studied population believed that society was supportive to tuberculosis patients. However $27.2 \%$ of them thought that they react friendly with tuberculosis patients but with avoiding them. $62.3 \%$ said that if they were diagnosed with tuberculosis they would be afraid and embarrassed, and $32.3 \%$ of them would feel sad and hopelessness, only $5.5 \%$ of participants would feel shameful as in table (2).

Regarding the effect of health education intervention on knowledge of the studied group. There were statistical significant improvement in knowing the mode of transmission of pulmonary $\mathrm{TB}$, place and duration of treatment, after the health education program $(\mathrm{p}<0.05)$. Before the health education program total knowledge score about pulmonary TB had Mean \pm SD (4.9 \pm 1.8$)$, median (5), and range (1-8). About $46.3 \%$ of the interviewed participants had satisfactory level of knowledge which increased to 94.4\%after intervention. However there was improvement in the total knowledge score after the health education program with mean \pm SD (7.7 \pm 0.966$)$, median (7), and range (4-9) Table (3).

A statistical significant difference was detected in the intended health-seeking behavior when the participants were asked what they would do if they thought they had pulmonary tuberculosis symptoms. Also, the person stigma showed statistical significant difference in the items of sadness and hopelessness $(p<0.05)$ table $(4)$. 
Table (1): Distribution of knowledge about pulmonary tuberculosis among studied group according to socio-demographic characteristic.

\begin{tabular}{|c|c|c|c|c|c|c|c|c|}
\hline \multirow{3}{*}{\multicolumn{2}{|c|}{ nowledge }} & \multicolumn{2}{|c|}{$\begin{array}{c}\text { Total } \\
\mathrm{N}(254)\end{array}$} & \multicolumn{2}{|c|}{$\begin{array}{l}\text { satisfactory } \\
\text { knowledge }\end{array}$} & \multicolumn{2}{|c|}{$\begin{array}{c}\text { Unsatisfactory } \\
\text { knowledge }\end{array}$} & \multirow[t]{3}{*}{$\mathrm{p}$} \\
\hline & & $\mathrm{N}$ & $\%$ & $\mathrm{~N}$ & $\%$ & $\mathrm{~N}$ & $\%$ & \\
\hline & & & & 98 & 38.6 & 156 & 61.4 & \\
\hline \multirow[t]{2}{*}{ Sex } & males & 128 & 50.3 & 57 & 44.5 & 71 & 55.4 & \\
\hline & Females & 126 & 49.7 & 41 & 32.5 & 85 & 67.5 & 0.049 \\
\hline \multirow[t]{2}{*}{$\overline{\text { Age }}$} & $\leq 40$ & 190 & 74.8 & 71 & 37.4 & 119 & 62.6 & \\
\hline & $>40$ & 64 & 25.2 & 27 & 42.2 & 37 & 57.8 & 0.4 \\
\hline \multirow[t]{4}{*}{ Social class } & & & & & & & & \\
\hline & High & 124 & 48.8 & 40 & 32.3 & 84 & 67.7 & \\
\hline & Middle & 80 & 31.5 & 33 & 41.3 & 47 & 58.7 & 0.079 \\
\hline & Low & 50 & 19.7 & 25 & 50 & 25 & 50 & \\
\hline \multirow[t]{2}{*}{ Residence } & rural & 200 & 78.7 & $\overline{78}$ & 39 & 122 & 61 & \\
\hline & Urban & 54 & 21.3 & 20 & 37 & 34 & 66 & 0.79 \\
\hline \multirow[t]{2}{*}{ Marital status } & married & 196 & 77.1 & 78 & 39.8 & 118 & 60.2 & \\
\hline & Others & 58 & 22.8 & 20 & 34.5 & 38 & 64.5 & 0.46 \\
\hline \multirow[t]{3}{*}{ Smoking } & smokers & 36 & 14.2 & 17 & 47.2 & 19 & 52.8 & \\
\hline & Ex-smoker & 22 & 8.7 & 9 & 40.9 & 13 & 59.1 & \\
\hline & Non- smoker & 196 & 77.1 & 72 & 36.7 & 124 & 63.3 & 0.48 \\
\hline
\end{tabular}

Figure(1): Percentage of knowledge about pulmonary tuberculosis among studied group during survey phase

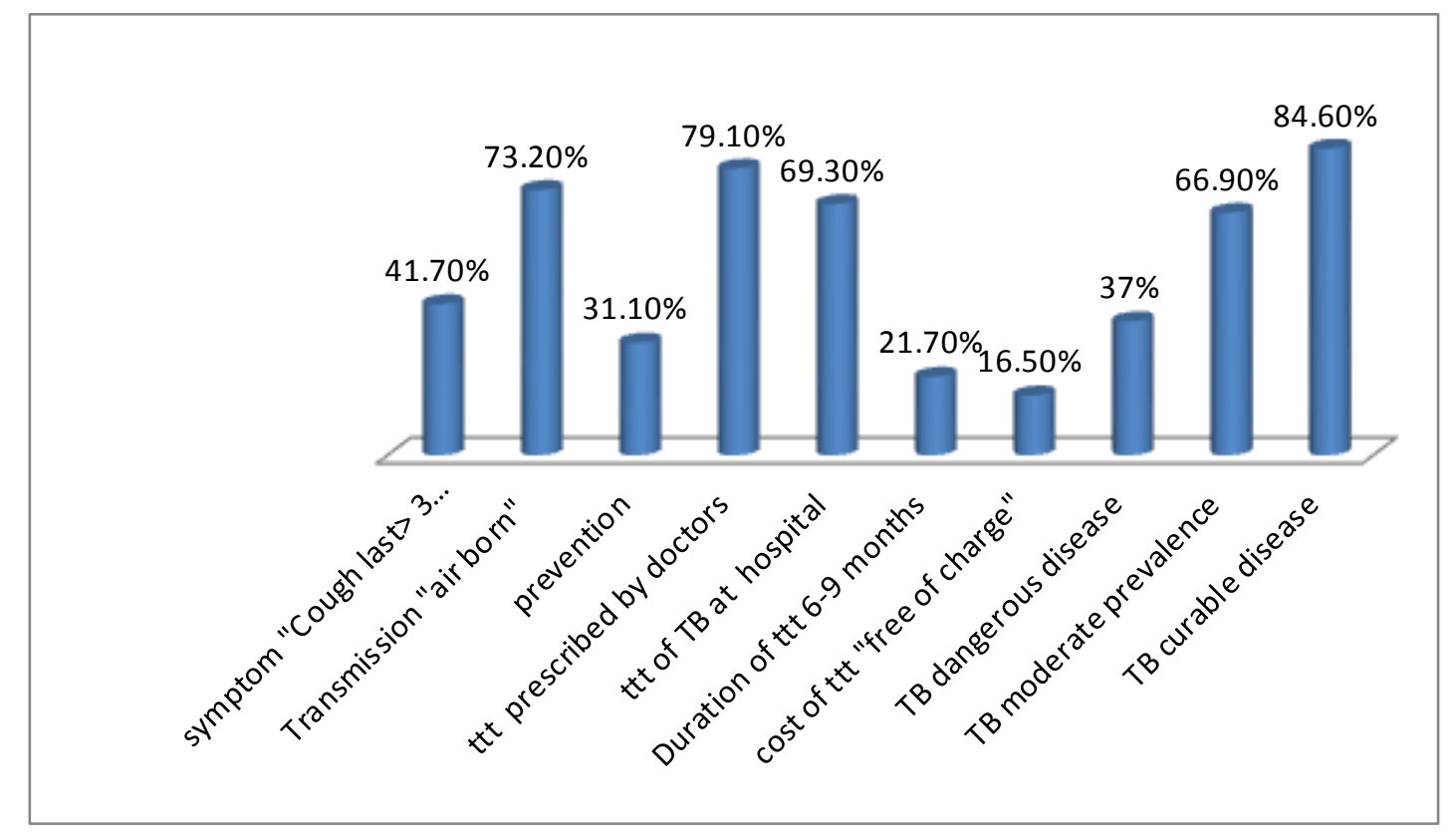


Table (2): Distribution of attitudes regarding pulmonary tuberculosis among the studied group during survey phase

\begin{tabular}{|c|c|c|}
\hline Variables & Number & $\%$ \\
\hline $\begin{array}{l}\text { What you do if you suspect you have symptoms of TB(intended health } \\
\text { seeking behavior) }\end{array}$ & & \\
\hline - Health facility & 207 & 81.5 \\
\hline - Pharmacy & 26 & 10.2 \\
\hline - Traditional healer & 21 & 8.3 \\
\hline When will you go to a health facility (intended health seeking behavior) & & \\
\hline - When I feel symptoms & 138 & 54.3 \\
\hline - Continuous symptoms more than 3 weeks & 50 & 19.7 \\
\hline - If I realize that the symptoms are pulmonary tuberculosis & 59 & 23.2 \\
\hline - I would not go to doctors & 7 & 2.8 \\
\hline How is a TB patient regard in your community & & \\
\hline - Most people reject & 32 & 12.6 \\
\hline - Most people friendly but avoid & 69 & 27.2 \\
\hline - Most people support and help him & 153 & 60.2 \\
\hline $\begin{array}{l}\text { How would your reaction if you were discovered that you have pulmonary } \\
\text { tuberculosis (personal stigma) }\end{array}$ & & \\
\hline - Fear and embarrassment & 158 & 62.3 \\
\hline - Shame & 14 & 5.5 \\
\hline - Sad and hopelessness & 82 & 32.3 \\
\hline
\end{tabular}

Table (3): Effect of health education program about pulmonary tuberculosis one knowledge of studied group

\begin{tabular}{|c|c|c|c|c|c|}
\hline \multirow[t]{2}{*}{ Knowledge } & \multicolumn{2}{|c|}{ Before( 54) } & \multicolumn{2}{|c|}{ After ( 54)* } & \multirow[t]{2}{*}{$\mathrm{p}$} \\
\hline & $\mathrm{N}$ & $\%$ & & $\%$ & \\
\hline Symptoms: & & & & & \\
\hline Cough last> 3 weeks & 19 & 35.2 & 17 & 31.5 & $>0.05$ \\
\hline Transmission of pulmonary $T B$ & & & & & \\
\hline Through the air if person cough or sneeze & 32 & 29.3 & 51 & 94.4 & $*<0.05$ \\
\hline Prevention & & & & & \\
\hline$\overline{\text { Covering mouth and nose }}$ & 24 & 44.4 & 34 & 62.9 & $>0.05$ \\
\hline TTT OF TB & & & & & \\
\hline Treatment prescribed by doctors & 30 & 55.5 & 53 & 98.1 & $*<0.05$ \\
\hline place of ttt: & & & & & \\
\hline governmental hospital & 26 & 48.1 & 53 & 98.1 & $*<0.05$ \\
\hline duration of treatment & & & & & \\
\hline 6- 9 months & 10 & 18.5 & 47 & 87 & $*<0.05$ \\
\hline Cost of ttt and diagnosis & & & & & \\
\hline Free of charge & 10 & 18.5 & 9 & 16.7 & $>0.05$ \\
\hline TB seriousness & & & & & \\
\hline Dangerous & 19 & 35.2 & 14 & 25.9 & $>0.05$ \\
\hline Prevalence of TB & & & & & \\
\hline *Moderate prevalence & 34 & 62.9 & 41 & 75.9 & $>0.05$ \\
\hline curable disease & & & & & \\
\hline yes & 42 & 77.7 & 50 & 92.6 & $>0.05$ \\
\hline
\end{tabular}

* 6 subjects were dropped out at posttest \& excluded from analysis. Total knowledge score before health education program mean \pm SD $(4.9 \pm 1.8)$ median (5) range (1-8) . percent of participants had satisfactory level of knowledge before health education program were (46.3\%).Total knowledge score after health education program mean $\pm \mathrm{SD}(7.7 \pm 0.966)$ median (7) range (4-9) . percent of participants had satisfactory level of knowledge after health education program were $(94.4 \%)$. P value computed by Mc Nemar chi square test . *p statistically significant. 
Table (4): Effect of health education program on attitudes regarding tuberculosis among the studied group

\begin{tabular}{|c|c|c|c|c|c|}
\hline \multirow[t]{2}{*}{ Variables } & \multicolumn{2}{|c|}{ Before(54) } & \multicolumn{2}{|c|}{ After(54) } & \multirow[b]{2}{*}{$\mathrm{p}$} \\
\hline & $\mathrm{N}$ & $\%$ & $\mathrm{~N}$ & $\%$ & \\
\hline $\begin{array}{l}\text { What do you if you suspect you had symptoms of } \\
\text { TB(intended health seeking behavior } \\
\text { • Health facility } \\
\text { • } \text { Pharmacy } \\
\text { - Traditional healer }\end{array}$ & $\begin{array}{c}37 \\
14 \\
3\end{array}$ & $\begin{array}{c}68.5 \\
25.9 \\
5.6\end{array}$ & $\begin{array}{c}51 \\
1 \\
2\end{array}$ & $\begin{array}{c}94.4 \\
1.9 \\
3.7\end{array}$ & $\begin{array}{l}<0.05^{*} \\
<0.05^{*} \\
>0.05\end{array}$ \\
\hline $\begin{array}{l}\text { When will you go to a health facility (intended health } \\
\text { seeking behavior) } \\
\qquad \text { When I feel symptoms } \\
\text { - Continuous symptoms more than } 3 \text { weeks } \\
\text { - If you realize that the symptoms are pulmonary } \\
\text { tuberculosis }\end{array}$ & $\begin{array}{l}26 \\
14 \\
14\end{array}$ & $\begin{array}{l}48.2 \\
25.9 \\
25.9\end{array}$ & $\begin{array}{l}28 \\
20 \\
6\end{array}$ & $\begin{array}{l}51.9 \\
37.0 \\
11.1\end{array}$ & $\begin{array}{l}>0.05 \\
>0.05 \\
>0.05\end{array}$ \\
\hline $\begin{aligned} \text { How is a TB patient regard in your community } \\
\bullet \text { Most people reject } \\
\bullet \quad \text { Most people friendly but avoid } \\
\bullet \quad \text { Most people support and help him } \\
\end{aligned}$ & $\begin{array}{l}13 \\
23 \\
18 \\
\end{array}$ & $\begin{array}{l}24.1 \\
42.6 \\
33.3 \\
\end{array}$ & $\begin{array}{l}16 \\
23 \\
15\end{array}$ & $\begin{array}{l}29.6 \\
42.6 \\
27.8 \\
\end{array}$ & $\begin{array}{l}>0.05 \\
>0.05 \\
>0.05\end{array}$ \\
\hline $\begin{array}{l}\text { How would your reaction if you were found out that you } \\
\text { have TB(personal stigma) } \\
\qquad \text { Fear and embarrassment } \\
\text { - Shame } \\
\text { - Sad and hopelessness }\end{array}$ & $\begin{array}{l}30 \\
8 \\
16\end{array}$ & $\begin{array}{l}55.6 \\
14.8 \\
29.6\end{array}$ & $\begin{array}{l}34 \\
13 \\
7\end{array}$ & $\begin{array}{l}62.9 \\
24.1 \\
13.0\end{array}$ & $\begin{array}{l}>0.05 \\
>0.05 \\
<0.05^{*}\end{array}$ \\
\hline
\end{tabular}

*P statistically significant

Figure (2): Sources of knowledge regarding pulmonary tuberculosis among studied group

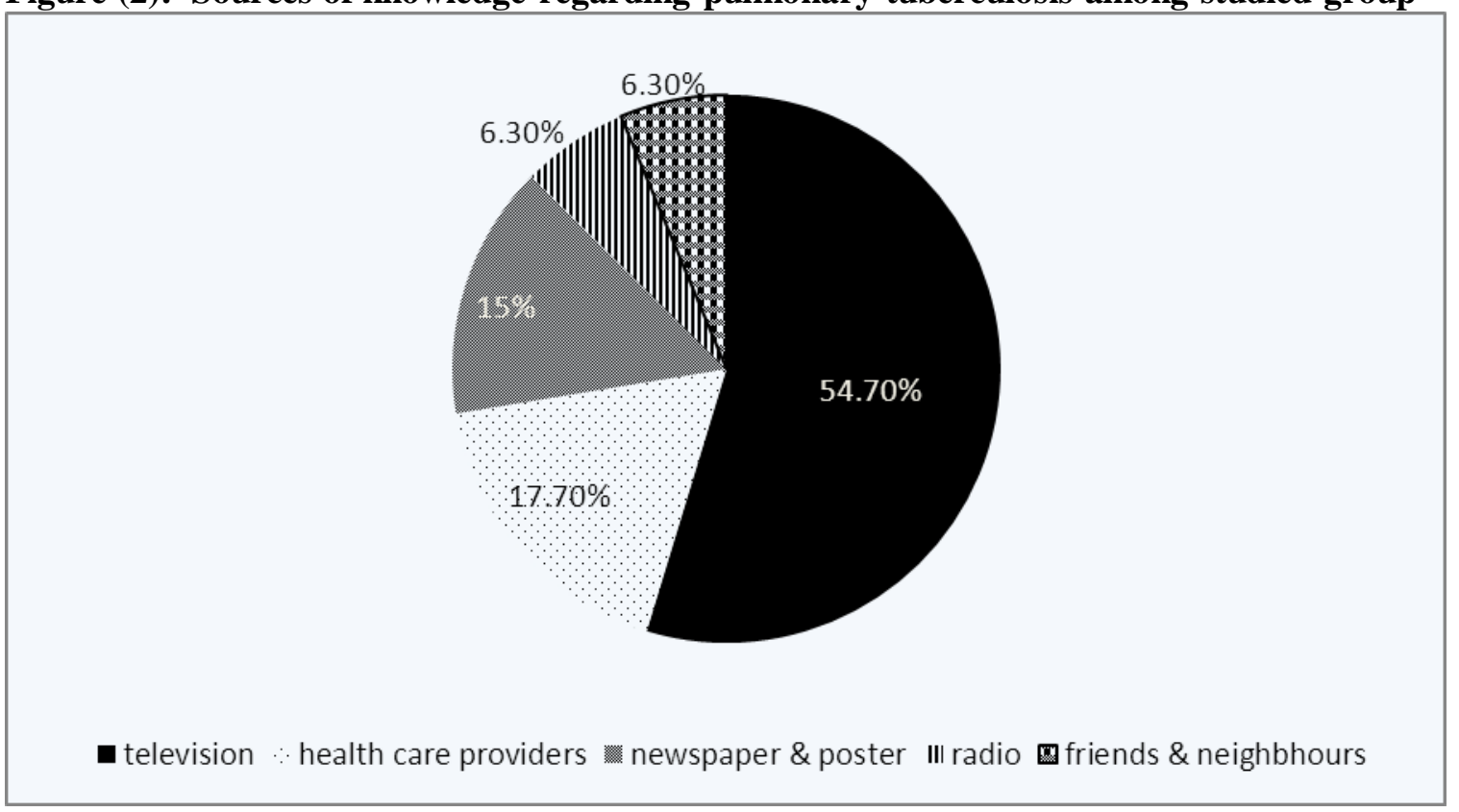

\section{DISCUSSION}

TB is re-emerging as a global public health problem. Public health efforts should primary directed towards primary preventive measures mainly improving awareness of population. Health education as an integral part of the overall control process of TB. Health education must target all members of the community.

As regard the symptoms of pulmonary tuberculosis less than half of the respondents in this study identified cough more than three weeks as the presenting complaint of pulmonary 
tuberculosis. This finding is in accordance with Khan et al (2006) [11] who reported that Cough $>3$ weeks was mentioned by less than half of the respondents. This finding is an important point in national control program in Egypt, as it depends on passive case finding.

About three quarters of the studied subjects had correct knowledge about mode of transmission of pulmonary tuberculosis, and its place of treatment. This result is consistent with Mustaq et al (2011)[12] who found that, the majority of studied group in Pakistan had correct knowledge about mode of transmission, treatment and place of treatment of tuberculosis, where national programs of tuberculosis are applied in both countries.

Regarding awareness of the studied group about the methods of prevention of pulmonary tuberculosis, only one third of them mentioned that covering mouth and nose during sneezing and cough. About one quartile reported vaccination as a preventive measure for pulmonary tuberculosis and prohibition of promiscuous spill on ground was reported by $28 \%$ of studied group. In agreement with Yousif et al (2009)[13] who found that a considerable proportion of participants did not know the method of prevention of tuberculosis. Ignorance of the facts that the disease is an airborne and contagious one has the consequence of increasing transmission of the disease. As patients will not care of adopting control measures in their households and/or workplace.

The current study found that one fifth of the studied group knew the correct duration of treatment of pulmonary tuberculosis. The Egyptian study of Morsy et al(2003)[7] revealed that the significant risk factor for treatment failure was the non-compliance to treatment, due to lack of awareness about the duration of standard treatment of pulmonary tuberculosis. A similar study in Sudan reported that about one half of patients knew the actual duration of treatment[14]. This can be explained by the fact that patients must be oriented by the duration of treatment for better compliance to treatment.

This study found that only $16.6 \%$ of the studied group knew that diagnosis and treatment of pulmonary tuberculosis are free of charge. This agreed with the study of Wang et al (2008)[15] .Mustaque et al(2010)[9]who found that small proportion of studied group knew that diagnosis and treatment of pulmonary tuberculosis are free of charge. lack of awareness that diagnosis and treatment of pulmonary tuberculosis free of charge lead to delay of seeking for diagnosis and treatment of pulmonary tuberculosis.

In agreement with the study of Yousif et al(2009)[13], the majority of the studied group (84.6\%) declared that pulmonary tuberculosis is a curable diseases. Moreover two thirds of the studied group reported that pulmonary tuberculosis is a moderate prevalent disease in Egypt and about two fifths of the studied group announced that pulmonary tuberculosis is a serious disease.

In agreement with a study in Pakistan done by Mustaque et al (2011)[12] the main information sources about pulmonary tuberculosis were television and health care providers. Other sources, as radio newspapers, posters, family and friends. This can be explained as television plays a vital role in the community health education program about pulmonary tuberculosis and the wide spread of television in every house at any time.

The present study found that, the majority of the studied group $(81.5 \%)$ answered the question What they do if they suspect that they have symptoms of TB (intended health seeking behavior), by they would go to a health facility. In agreement with ; the studies of Enwuru et al (2002)[16], Hoa et al (2003)[17] and Mustaque et al (2011)[12]found that most respondents would go to health facility as soon as they realize that they had symptoms of pulmonary tuberculosis. About one half of the studied group would go if they felt symptoms, the other half would go to health facility after persistent symptoms or if they became sure that symptoms of pulmonary tuberculosis. This behavior will lead to late case finding and more spread of the disease.

On studying personal stigma about pulmonary tuberculosis. The majority of the studied group would feel fear ,embarrassed, a shamed and hopelessness if they discovered that they having pulmonary tuberculosis. The same results reported by the studies of Singh et al (2002)[18] , Yousif et al(2009)[13] and Mustaque et al (2011)[12]. This can be explained by the fact that pulmonary tuberculosis is a disease associated with poverty and low socioeconomic level. The point of view of society that condemned tuberculosis patients. 
Although community stigma from a perceived tuberculosis infection, $60.2 \%$ of respondents believed that people should be support and help pulmonary tuberculosis patients . About one third of respondents, thought that people should be friendly to pulmonary tuberculosis patients with avoided them. Only $12.6 \%$ of respondents believed that people must reject the pulmonary tuberculosis patients. Disagreement with the study of Mustaque et al (2011)[12] who found that nearly one half of the studied group believed that the community reject of pulmonary tuberculosis patients . Our finding can explained by culture of humanity of Egyptian population.

This study revealed that $38.6 \%$ of studied group had satisfactory knowledge about pulmonary tuberculosis, in agreement with the study of Ali et $\mathrm{al}(2003)$ [19] and Mushtaq et al (2010)[9] who found that low awareness of Pakistan population about TB . Also others studies found that low awareness of African population about tuberculosis[20,21]. But the percent of awareness of population in the present study was three times more than Philipinian population [22]. This finding may be due to discrepancy of health education programs were offered to different population.

The present study found that the health education program increased mean knowledge score about pulmonary tuberculosis from $4.9 \pm 1.8$ to7.7 \pm 0.97 . The percentage of studied group had satisfactory knowledge about pulmonary tuberculosis was doubled after health education program . As regard seeking health behavior, health education program increase attitude to go a health facility and decrease other choices as go to pharmacy or traditional healers. Also significant decrease in feeling of sadness and hopelessness associated with expectation of pulmonary tuberculosis among a studied group. In agreement with Croft and Croft(1999) [23] and Khan et al[24] who found that well - conducted community education campaigns had shown to produce favorable outcome In Bangladesh . It is of great importance for the patients to know that TB is curable with regular treatment. This will psychologically encourage them to abide by their treatment instructions. Patients' knowledge about the duration of treatment needed to cure the disease is an important educational message. As the bacteria needs 6-8 months for full clearance from host tissues[25]. The health education intervention of current study, improved awareness of studied group about mode of transmission ,treatment, place of treatment and duration of treatment of pulmonary tuberculosis. In addition, intended health seeking behavior was improved as they would go to a health facility; other choices were nearly neglected.

\section{CONCLUSION}

The survey results showed that the overall knowledge regarding TB was low among the studied population. After the health education program there was betterment of correct knowledge regarding TB among the studied group. Most of respondents knew about mode of transmission, the correct duration of TB treatment . Health education program improved their attitude regarding the disease and its treatment.

\section{Recommendations:}

- The study indicated the need of implementing frequent health educational programs, to improve population awareness and attitude about pulmonary tuberculosis .

- Mass media Health education must be considered an integral part of the overall control process of tuberculosis .

- Further researchers are needed using other methods of health education.

\section{Funding: Non .}

\section{Conflicts of interest: Non .}

Ethical issues: Permission was obtained from Sharkia Health Directorate to conduct the study. Informed oral consent was obtained from each person to participate in the current work after explanation of its objectives. Total confidentiality of any information was secured. The intervention have no harmful effect on participants, and they were informed about their right to withdraw at any time.

\section{REFERENCES}

1. WHO . Global tuberculosis control: WHO report 2010 a.

2. Parsons LM, A'kos SA, Gutierrez C, Lee E, Paramasivan CN, Abimiku A, Spector S, Roscigno, G, Nkengasong, J . Laboratory Diagnosis of Tuberculosis in Resource-Poor Countries: Challenges and Opportunities. Clinical Microbiology Reviews 2011; 24: 314-350.

3. World Health Organization .The Stop TB Strategy: building on and enhancing DOTS to meet the TB-related Millennium Development Goals. Geneva, (WHO/HTM/TB/2006.368). 
4. International standards for tuberculosis care and control. The Hague, Tuberculosis Coalition for Technical Assistance. www.who.int/tb/publication/2006 access 10 march 2012

5. WHO . Stop TB Partnership and World Health Organization. Global Plan to Stop TB 20112015. WHO, Geneva: 2010b

6. National tuberculosis program (NTP guideline in TB control for nurses) http://www.emro.who.int/stb/egypt/publications_ guidelines_Nurse_NTP.htm access 8 February 2012

7. Morsy AM, Zaher HH, Hassan MH, Shouman A .Predicators of treatment failure among tuberculosis patients under DOTS strategy in Egypt. Eastern Mediterranean Health Journal 2003; 9(4): 689-701.

8. Lönnroth K, Castro KG, Chakaya JM, Chauhan LS, Floyd K, Glaziou P, et al. Tuberculosis control and elimination 2010-50: cure, care, and social development. Lancet 2010; 375:18141829.

9. Mushtaq U M ., Majrooh A M ., Ahmad W ., Rizwan M ., Luqman M Q ., Aslam J M ., Siddiqui M A ., Akram J, Shad A M . Knowledge, attitudes and practices regarding tuberculosisin two districts of Punjab, Pakistan. Int $j$ tuberc lung dis 2010;14(3):303-310

10. World Health Organization. Advocacy, communication and social mobilization for TB control: a guide to developing knowledge, attitude and practice surveys. WHO/HTM/STB/2008.46. Accessed September 2011

11. Khan J A, Irfan M, Zaki A, Beg M, Hussain S F, Rizvi N. Knowledge, attitude and misconceptions regarding tuberculosis in Pakistani patients. J Pak Med Assoc 2006; 56: 211-214.

12. Mushtaq UM, Shahid U, Abdullah MH, Saeed A, Fatima O F, Shad AM, Siddiqui MA, Akram J. Urban-rural inequities in knowledge, attitudes and practices regarding tuberculosis in two districts of Pakistan's Punjab province. International Journal for Equity in Health 2011 http://www.equityhealthj.com/content/10/1/8

13. Yousif KT ,Al Khayat MI, Salman HD. Survey of knowledge , attitude and practices: Enhanced response to TB ACSM ,Iraq . Middle east journal of family medicine 2009; 7 (1 ):23-38

14. Mohamed A, Yousif AM, Ottoa P,Bayoumi A. Knowledge of Tuberculosis: A Survey among Tuberculosis Patients in Omdurman, Sudan .
Sudanese journal of public health January 2007;. 2(1):21 -28

15. Wang J, Fei Y, Shen H, Xu B. Gender difference in knowledge of tuberculosis and associated health-care seeking behaviors: a cross sectional study in a rural area of China. BMC Public Health 2008; 8:354.

16. Enwuru CA, Idigbe EO, Ezeobi NV, Otegbeye AF. Care-seeking behavioural patterns, awareness and diagnostic processes in patients with smear and culture-positive pulmonary tuberculosis in Lagos, Nigeria. Trans R Soc Trop Med Hyg 2002 ; 96:614-6.

17. Hoa NP, Thorson AE, Long NH, Diwan V K. Knowledge of tuberculosis and associated healthseeking behaviour amongrural Vietnamese adults with a cough for at least three weeks. Scand $J$ Public Health 2003; 62 (Suppl): S59-S65

18. Singh MM, Bano T, Pagare D, Sharma N, Devi R Mehra M. Knowledge and attitude towards tuberculosis in a slum community of Delhi. $J$ Commun Dis 2002; 34: 203-214.

19. Ali SS, Rabbani F , Siddiqui UN. Tuberculosis: do we know enough? A study of patients and their families in an outpatient hospital setting in Karachi, Pakistan. Int J Tuberc Lung Dis 2003 ; 7: 1052-1058.

20. Lienhardt C, Rowley J, Manneh K, Lahai G, Needham D, Milligan P. Factors affecting time delay to treatment in a tuberculosis control program in a sub-Saharan African country: the experience of The Gambia. Int J Tuberc Lung Dis 2001; 5(3):233-9.

21. Ouedraogo M, Kouanda S, Boncoungou K, Dembele M, Zoubga ZA, , Ouedraogo SM. Treatment seeking behavior of smear positive tuberculosis patients diagnosed in Burkina Faso. Int J Tuberc Lung Dis 2006; 10(2):184-7

22. Tupasi TE, Radhakrishna S, Co VM, Villa ML, Quelapio MI, Mangubat NV et al . , Bacillary disease and health seeking behavior among Fillipnos with symptoms of tuberculosis : implication for control. Int J Tuberc lung Dis $2000 ; 4: 1126-1132$

23. Croft RP , Croft RA. Knowledge, attitude and practice regarding leprosy and tuberculosis in Bangladesh. Lepr Rev1999, 70:34-42

24. Khan MA, Walley J, Newell J, Imdad N. Tuberculosis in Pakistan: sociocultural constraints and opportunities in treatment. Soc Sci Med 2000; 50:247-254.

25. Rieder L H . Intervention for Tuberculosis control and Elimination. International Union against Tuberculosis and Lung Disease. Paris, France: Boulevard Saint Michel.2002. 